\title{
Epigenetic regulation of proliferation and invasion in hepatocellular carcinoma cells by CBP/p300 histone acetyltransferase activity
}

\author{
YUJI INAGAKI $^{1}$, KATSUYA SHIRAKI ${ }^{1}$, KAZUSHI SUGIMOTO ${ }^{1,2}$, TAKAZUMI YADA ${ }^{1}$, MASAHIKO TAMEDA ${ }^{1}$, \\ SUGURU OGURA $^{1}$, NORIHIKO YAMAMOTO ${ }^{1}$, YOSHIYUKI TAKEI ${ }^{1}$ and MASAAKI ITO ${ }^{3}$ \\ Departments of ${ }^{1}$ Gastroenterology and Hepatology, ${ }^{2}$ Molecular and Laboratory Medicine, ${ }^{3}$ Cardiology and Nephrology, \\ Mie University Graduate School of Medicine, Tsu, Mie 514-8507, Japan
}

Received September 16, 2015; Accepted October 23, 2015

DOI: $10.3892 /$ ijo.2015.3288

\begin{abstract}
Altered epigenetic control of gene expression plays a substantial role in tumor development and progression. Accumulating studies suggest that somatic mutations of CREB binding proteins (CBP)/p300 occur in some cancer cells. CBP/ p300 possess histone acetyltransferase (HAT) activity, and are involved in many cellular processes. In this study, we investigated the expression and functional role of $\mathrm{CBP} / \mathrm{p} 300$ in hepatocellular carcinoma (HCC) using the specific inhibitor C646 of CBP/p300 HAT activity. We examined its effect on several apoptosis-related proteins and invasion-related genes. The results showed that $\mathrm{CBP} / \mathrm{p} 300$ were highly expressed in HCC tissues and that expression of p300, but not of CBP, was strongly correlated with the malignant character of HCC. C646 inhibited proliferation of HCC cell lines in a dose dependent manner. C646 significantly augmented TRAIL-induced apoptotic sensitivity, which was accompanied by reduced levels of survivin, in HepG2, HLE and SK-HEP1 cells. C646 significantly inhibited invasion of Huh7, HLE and SK-HEP1 cells. The level of matrix metallopeptidase 15 (MMP15) mRNA expression was significantly reduced, whereas the level of laminin alpha 3 (LAMA3) and secreted phosphoprotein 1 (SPP1) mRNA expression was significantly increased in Huh7 cells following exposure to C646. In conclusion, our results suggest that $\mathrm{CBP} / \mathrm{p} 300$ HAT activity has an important role in malignant transformation, proliferation, apoptotic sensitivity and invasion in HCC. CBP/p300 could be a promising therapeutic target in HCC.
\end{abstract}

Correspondence to: Dr Katsuya Shiraki, Department of Gastroenterology, Mie Graduate University School of Medicine, 2-174 Edobashi, Tsu, Mie 514-8507, Japan

E-mail: katsuyas@clin.medic.mie-u.ac.jp

Key words: hepatocellular carcinoma, histone acetyltransferase, CREB binding protein, p300, C646

\section{Introduction}

Epigenetics is defined as the inheritance of information based on gene expression levels as opposed to genetics, which refers to information inherited on the basis of gene sequences. Recent studies have shown that altered epigenetic control of gene expression plays a substantial role in many different diseases, including tumor development and progression (1-3). Unlike genetic mutations, changes in the epigenome associated with cancer are potentially reversible. Novel therapies targeting epigenetic pathways are already used in clinical cancer treatment or are currently in preclinical and clinical trials (3). Histone acetylation is a key epigenetic mechanism. Histone proteins assemble with DNA in nucleosomes that function as transcriptional regulators. The $\mathrm{N}$-terminal tails of histones undergo acetylation on specific residues. Acetylation of lysines is regulated by the opposite action of histone acetyltransferase (HAT) and histone deacetylases (HDAC) enzymes.

CREB binding protein (CBP) and p300 belong to the HAT family. $\mathrm{CBP} / \mathrm{p} 300$ are transcriptional coactivators for many important transcription factors. Through their HAT activity, they relax chromatin structure and make chromosomal DNA accessible (4). The HAT activity of $\mathrm{CBP} / \mathrm{p} 300$ also acetylates a number of non-histone transcription factors, which can positively or negatively modulate their activity through diverse mechanisms. $\mathrm{CBP} / \mathrm{p} 300$ have at least 400 interacting partners and act as hubs in gene networks (5). Through their interaction with diverse transcriptional factors, $\mathrm{CBP} / \mathrm{p} 300$ are involved in many cellular processes such as DNA repair, cell growth, differentiation, and apoptosis (6).

Somatic mutations of $\mathrm{CBP} / \mathrm{p} 300$ occur in some malignancies. For example, chromosomal translocations directly involving CBP or p300 genes are associated with leukemia $(7,8)$. Bi-allelic somatic mutations in the p300 gene have been occasionally observed in gastric, colon and breast cancers, and truncating mutations in p300 were detected in primary tumors and tumor cell lines $(9,10)$. Mice with mono-allelic inactivation of the CBP gene, but not of the p300 gene, develop an increased incidence of hematological malignancies (11). In a study of chimeric mice, hematological malignancies emerged from both $\mathrm{CBP}^{-/}$and $\mathrm{p} 300^{-/-}$cell populations. This 
finding suggests that both CBP and p300 appear to play a role in suppressing hematological tumor development (12). Accumulating scientific evidence indicates that $\mathrm{CBP} / \mathrm{p} 300$ play a role in cancer phenotype. $\mathrm{CBP} / \mathrm{p} 300$ promoted cancer progression in colon cancer cell lines with microsatellite instability (13). Furthermore, p300 regulated p53-dependent apoptosis after DNA damage in colon cancer cells (14) and p300 disruption promoted epithelial to mesenchymal transition and an agressive cancer phenotype (15).

Hepatocellular carcinoma (HCC) is a global health concern due to its prevalence and dismal prognosis. The role of epigenetic deregulation in HCC is being increasingly recognized (16-18). However, as far as we know, there have been few studies on the functional significance of CBP/p300 HAT activity in HCC. The selective small molecule inhibitor C646 of $\mathrm{CBP} / \mathrm{p} 300$, was identified in a virtual ligand screen (19). C646 has been used to study p300 HAT function in prostate cancer (20), melanoma (21), non-small cell lung cancer (22), and acute myeloid leukemia (23). These studies indicated that $\mathrm{CBP} / \mathrm{p} 300$ play an important role in cancer cell progression.

Therefore, in this study, we investigated the impact of $\mathrm{CBP} / \mathrm{p} 300 \mathrm{HAT}$ activity in HCC and the possibility that $\mathrm{CBP} / \mathrm{p} 300$ may be a promising therapeutic target in HCC.

\section{Materials and methods}

Cell lines and reagents. The human HCC cell line SK-HEP1 was purchased from the American Type Culture Collection (Rockville, MD, USA). The human HCC cell lines HepG2, HLE and Huh7 were purchased from the Health Science Research Resource Bank (Osaka, Japan). All cell lines were cultured in Dulbecco's modified Eagle's medium (DMEM) supplemented with $1 \%$ penicillin/streptomycin and $10 \%$ fetal calf serum (FCS) (all from Life Technologies, Tokyo, Japan).

The EP300 monoclonal antibody was purchased from Abnova (Taipei, Taiwan). The CBP rabbit monoclonal antibody was purchased from Cell Signaling Technology (Denver, MA, USA). C646 was purchased from Sigma-Aldrich (St. Louis, MO, USA), and was dissolved in dimethyl sulfoxide (DMSO). Recombinant human TRAIL was purchased from R\&D Systems (Minneapolis, MN, USA).

Immunohistochemistry. Immunohistochemical staining for CBP and p300 was performed on tissue arrays (Super Bio Chips, Seoul, Korea) using a TSA Biotin system (Perkin Elmer, Waltham, MA, USA). Deparaffinized sections were heated for $15 \mathrm{~min}$ in citrate buffer at $120^{\circ} \mathrm{C}$ in an autoclave to reactivate the antigen and were then treated with $0.3 \% \mathrm{H}_{2} \mathrm{O}_{2}$ in methanol for 20 min to deactivate endogenous peroxidases. Sections were blocked with TNB blocking buffer (0.1 M Tris- $\mathrm{HCl} \mathrm{pH} 7.5,0.15 \mathrm{M} \mathrm{NaCl}, 0.5 \%$ blocking reagent) for $30 \mathrm{~min}$, covered with primary antibody at $4^{\circ} \mathrm{C}$ overnight, covered with second-step biotinylated antibody for $60 \mathrm{~min}$, and then incubated with streptavidin-horseradish peroxidase (HRP) for $30 \mathrm{~min}$. After washing, sections were incubated with the biotinyl tyramide amplification reagent for $10 \mathrm{~min}$. After washing, sections were incubated with streptavidin-HRP for $30 \mathrm{~min}$ and were then incubated with diaminobenzidine (DAB) (Dojindo, Rockville, MD, USA) $/ 0.15 \% \mathrm{H}_{2} \mathrm{O}_{2}$ and counterstained with hematoxylin
(Muto Pure Chemicals, Tokyo, Japan). Staining was observed under a microscope (BZ-X710; Keyence, Osaka, Japan).

Detection of histone acetylation by immunoblotting. HCC cells were incubated at $37^{\circ} \mathrm{C}$ in a $5 \% \mathrm{CO}_{2}$ atmosphere. Cells were treated with $\mathrm{C} 646(0,20$ and $50 \mu \mathrm{M})$ for $6 \mathrm{~h}$ following which histones were isolated using the EpiQuik Total Histone Extraction kit (Epigentek, Brooklyn, NY, USA) according to the manufacturer's instructions. The protein content of each sample was measured using the Bio-Rad protein assay kit (Bio-Rad Laboratories, Hercules, CA, USA). Aliquots from each sample containing equal amounts of protein were separated by sodium dodecyl sulfate (SDS)-polyacrylamide gel (PAGE) electrophoresis and transferred onto polyvinylidene difluoride (PVDF) membranes (Millipore, Billerica, MA, USA) for immunoblotting as described previously (24). The following primary antibodies were used: anti-acetyl-histone $\mathrm{H} 3$ (1:10,000) and anti-histone H3 (1:20,000) (Millipore). Signals were detected with the appropriate second antibodies and an ECL kit (Amersham Pharmacia Biotech, Bucks, UK).

Cell proliferation and viability assay. MTT assay. HCC cells were plated at a density of $5 \times 10^{3}$ cells/well in 96-well microtiter plates (Corning Glass Works, Corning, NY, USA), and each plate was incubated at $37^{\circ} \mathrm{C}$ in a $5 \% \mathrm{CO}_{2}$ atmosphere. After incubation for $24 \mathrm{~h}, 50 \mu \mathrm{l}$ of drug solution was added, and the plates were incubated for an additional 24 or $48 \mathrm{~h}$ according to the experiments. The live-cell count was determined using a Cell Titer 96 assay kit (Promega, Madison, WI, USA) according to the manufacturer's instructions. The absorbance of the contents of each well was measured at $570 \mathrm{~nm}$ with a microtiter plate reader (Bio-Rad Laboratories).

Detection of apoptosis-related proteins by immunoblotting. Expression of survivin, XIAP and Bcl-xL in HCC cell lines was analyzed using immunoblotting. Cells were harvested after incubation with C646 $(0,5,20$ and $50 \mu \mathrm{M})$ for $24 \mathrm{~h}$ and were lysed on ice with RIPA buffer (Thermo Fisher Scientific, Waltham, MA, USA). Aliquots from each sample containing equal amounts of protein were separated by SDS-PAGE and transferred onto PVDF membranes (Millipore) for immunoblotting. The following primary antibodies were used: anti- $\beta$-actin antibody (1:4,000) (ab8227; Abcam, Cambridge, MA, USA), anti-XIAP antibody $(1: 2,000)$, anti-Bcl-xL antibody $(1: 1,000)$ (both from BD Transduction Laboratories, Lexington, KY, USA) and anti-survivin antibody (1:50) (Santa Cruz Biotechnology, Inc., Santa Cruz, CA, USA). Signals were detected with the appropriate second antibodies and an ECL kit (Amersham Pharmacia Biotech).

Invasion assay. Changes in the invasion of HCC cells were analyzed using a BioCoat Matrigel Invasion chamber $(8 \mu \mathrm{m}$ pore-size; Corning, Bedford, MA, USA) according to the manufacturer's instructions. HCC cells $\left(5 \times 10^{4} /\right.$ well $)$ suspended in serum free media were seeded in the upper chamber with or without the indicated doses of C646. Ten percent FCS, acting as a chemoattractant, was placed in the lower chambers. After incubation for $22 \mathrm{~h}$ at $37^{\circ} \mathrm{C}$ in a $5 \% \mathrm{CO}_{2}$ atmosphere, the noninvaded cells on the upper surface were removed with a cotton swab. The invaded cells on the filter membrane were stained 
with Diff-Quick solution (Sysmex, Kobe, Japan). The invaded cells were counted under a microscope (Keyence) and five randomly chosen fields were counted for each assay.

Real-time-polymerase chain reaction (PCR) array. Changes in the expression of genes related to the migration and invasion of Huh7 cells following exposure to C646 (0 or $20 \mu \mathrm{M})$ for $24 \mathrm{~h}$ were analyzed using an $\mathrm{RT}^{2}$ PCR array (Human Extracellular Matrix and Adhesion Molecules) (SABiosciences Corp., Frederick, MD, USA) according to the manufacturer's instructions. Observed changes in mRNA expression were confirmed using quantitative real-time PCR.

Quantitative reverse transcription (RT)-PCR. Total RNA was extracted from $\sim 10^{7} \mathrm{Huh} 7$ cells using an RNeasy mini kit (Qiagen, Tokyo, Japan), and cDNA was synthesized by extension of oligo(dT) primers using PrimeScript reverse transcriptase (Takara, Ohtsu, Japan). Quantitative (qRT-PCR) was performed using an ABI PRISM 7300 Real-time PCR system (Applied Biosystems, Foster City, CA, USA) with EagleTaq Master Mix kits (Roche Molecular Systems, Branchburg, NJ, USA). The expression levels of target genes were determined from triplicate reactions by normalization of expression data to that of GAPDH. The primer sets for human matrix metallopeptidase 15 (MMP15), human laminin alpha 3 (LAMA3), human secreted phosphoprotein 1 (SPP1) and human GAPDH were as follows: human MMP15 forward, 5'-GCTGCTCCTGGTGCTTCT-3' and reverse, 5'-CTGAGG CAGGTAGCCATAAAG-3'; human LAMA3 forward, 5'-AGC CCGGGAAGCACTTAT and reverse, 5'-TGTCCATAGAGGC CGTGAC-3'; human SPP1 forward, 5'-GGGCTTGGTTGTC AGCAG-3' and reverse, 5'-CACTGCAATTCTCATGGTAG TGA-3'; human GAPDH forward, 5'-TATAAATTGAGCCCG CAGCC-3' and reverse, 5'-TTCCCGTTCTCAGCCTTGAC-3'.

Statistical analysis. Cell number and gene expression data were compared using the two-tailed Student's t-test. For analysis of differences between rates, the Chi-square test for independence was used. Cell invasion was compared using one-way ANOVA. A P-value $<0.05$ was considered statistically significant.

\section{Results}

CBP and p300 are expressed in HCC. We first performed immunohistochemical staining for CBP and p300 in tissue array samples. Results of the immunohistochemical analyses of CBP are summarized in Table I. The positive rates for CBP staining were extrahepatic metastatic HCC lesions $>\mathrm{HCC}$ primary lesions $>$ non-malignant liver tissues $(\mathrm{P}<0.01)$. However, there were no correlations between the degrees of cancer cell differentiation and positive staining for CBP. Fig. 1A-C show representative staining of CBP in non-malignant liver tissue, HCC primary lesion and extrahepatic metastatic HCC lesion, respectively. Results of the immunohistochemical analyses of p300 are summarized in Table II. The positive rates for p300 staining were extrahepatic metastatic HCC lesions $>$ HCC primary lesions $>$ non-malignant liver tissues $(\mathrm{P}<0.01)$. Additionally, there were statistical correlations between the degree of cancer cell differentiation and
Table I. Immunohistochemical analysis of CBP expression.

\begin{tabular}{lccc}
\hline & \multicolumn{3}{c}{ Extent of positive staining } \\
\cline { 2 - 4 } & $0-33 \%$ & $34-66 \%$ & $67-100 \%$ \\
\hline HCC (primary lesion) & $4(7 \%)$ & $21(34 \%)$ & $36(59 \%)$ \\
Well differentiated & $0(0 \%)$ & $6(10 \%)$ & $6(10 \%)$ \\
Moderately differentiated & $3(5 \%)$ & $12(20 \%)$ & $25(41 \%)$ \\
Poorly differentiated & $1(2 \%)$ & $3(5 \%)$ & $5(8 \%)$ \\
Extrahepatic metastatic & $0(0 \%)$ & $2(10 \%)$ & $19(90 \%)$ \\
HCC lesion & & & \\
Non-malignant liver & $2(22 \%)$ & $5(56 \%)$ & $2(22 \%)$ \\
\hline
\end{tabular}

CBP, CREB binding protein; HCC, hepatocellular carcinoma.

Table II. Immunohistochemical analysis of p300 expression.

\begin{tabular}{lccc}
\hline & \multicolumn{3}{c}{ Extent of positive staining } \\
\cline { 2 - 4 } & $0-33 \%$ & $34-66 \%$ & $67-100 \%$ \\
\hline HCC (primary lesion) & $11(18 \%)$ & $17(28 \%)$ & $33(54 \%)$ \\
Well differentiated & $5(8 \%)$ & $5(8 \%)$ & $2(3 \%)$ \\
Moderately differentiated & $5(8 \%)$ & $11(18 \%)$ & $24(39 \%)$ \\
Poorly differentiated & $1(2 \%)$ & $1(2 \%)$ & $7(11 \%)$ \\
Extrahepatic metastatic & $0(0 \%)$ & $1(1 \%)$ & $19(99 \%)$ \\
HCC lesion & & & \\
Non-malignant liver & $8(89 \%)$ & $1(11 \%)$ & $0(0 \%)$ \\
\hline
\end{tabular}

HCC, hepatocellular carcinoma.

positive staining for $\mathrm{p} 300(\mathrm{P}<0.05)$. Poorly differentiated HCC showed stronger p300 staining. Fig. 1D-F show representative staining of p300 in non-malignant liver tissue, HCC primary lesion and extrahepatic metastatic HCC lesion, respectively. CBP and p300 were also expressed in HepG2, Huh7, HLE and SK-HEP1 cells (data not shown). These results suggest that positive staining of CBP and p300 is a good marker of HCC and positive staining of p300 is a better marker of the malignant character of HCC than positive staining of CBP.

C646 reduces histone H3 acetylation in HCC cells. C646 has selective acetyltrasferase activity against CBP/p300 HAT. To assess the effect of C646 on global histone H3 acetylation in HCC cells, we used immunoblotting. Exposure of HepG2, Huh7, HLE and SK-HEP1 cells to C646 for $6 \mathrm{~h}$ resulted in dose-dependent reduction in global histone $\mathrm{H} 3$ acetylation (Fig. 2).

C646 reduces the proliferation of HCC cells. Next, to assess if $\mathrm{C} 646$ could affect HCC cell proliferation, we examined the effect of C646 on cancer cell number using an MTT assay (Fig. 3). Exposure of HepG2, Huh7, HLE and SK-HEP1 cells to C646 for $24 \mathrm{~h}$ resulted in decreased cell number in a dose-dependent manner. Moreover, nuclear fragmentation stained with 4,6-diamino-2-phenylindole (DAPI) was scarcely observed in SK-HEP1 cells treated with C646 (data not 
A

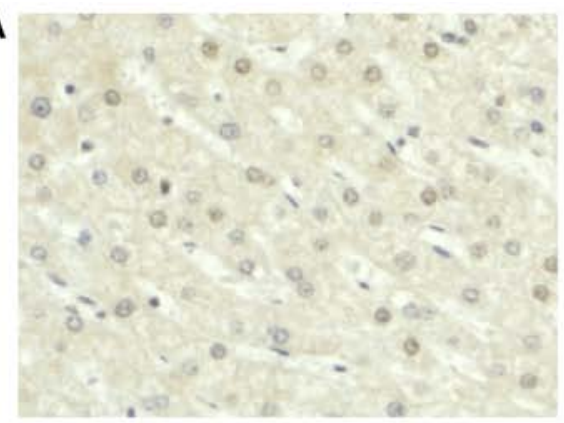

D

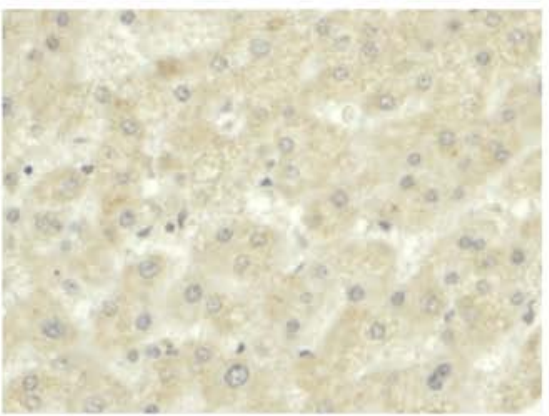

B

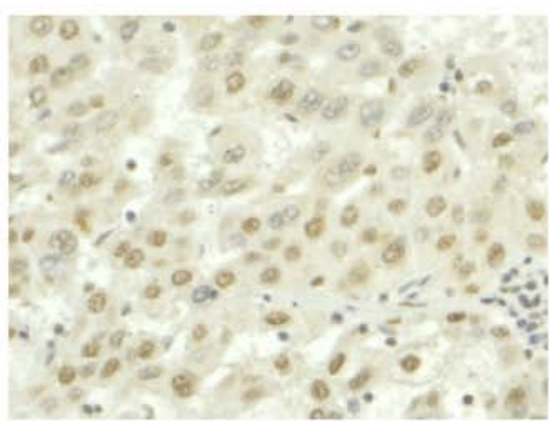

E .

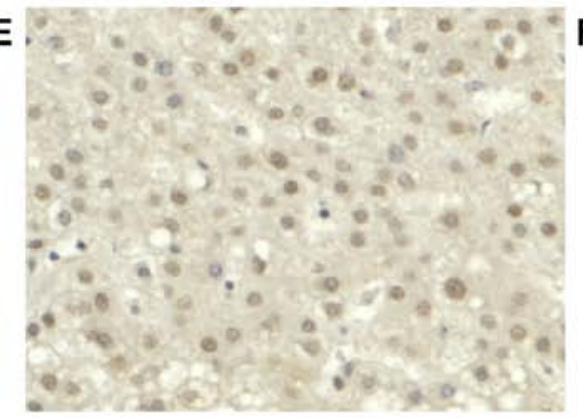

C
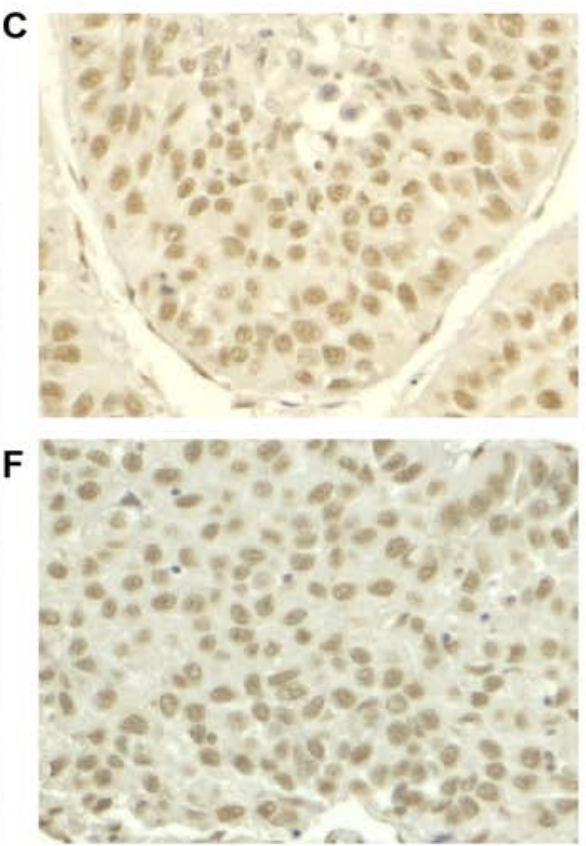

Figure 1. Immunohistochemical staining for CREB binding protein (CBP) and p300 in tissue array samples. Representative figures show (A) non-malignant liver tissue, (B) HCC primary lesion and (C) extrahepatic metastatic HCC lesion that were stained with anti-CBP antibody, and (D) non-malignant liver tissue, (E) HCC primary lesion and (F) extrahepatic metastatic HCC lesion that were stained with anti-p300 antibody. CBP and p300 staining were observed mainly in the nucleus. Objective lens magnification, x20, zoom, x3.

A

HepG2

$0 \mu \mathrm{M} 20 \mu \mathrm{M} 50 \mu \mathrm{M}$

acetyl-H3

total $\mathrm{H} 3$

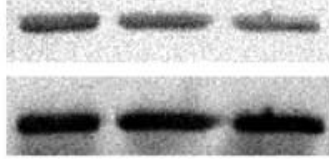

C

HLE

$0 \mu \mathrm{M} 20 \mu \mathrm{M} 50 \mu \mathrm{M}$

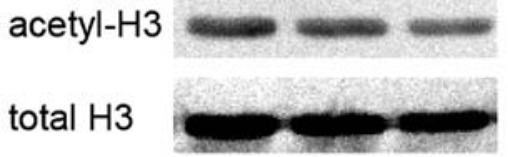

B

Huh7

$0 \mu \mathrm{M} 20 \mu \mathrm{M} 50 \mu \mathrm{M}$

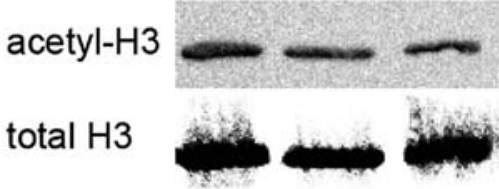

D

SK-HEP1

$0 \mu \mathrm{M} 20 \mu \mathrm{M} 50 \mu \mathrm{M}$

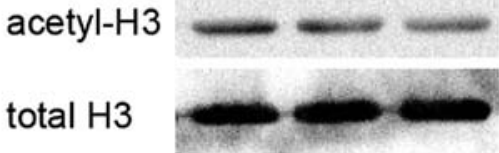

Figure 2. Effects of C646 on histone H3 acetylation in HCC cells. (A) HepG2 cells, (B) Huh7 cells, (C) HLE cells and (D) SK-HEP1 cells were treated for 6 h with increasing concentrations of $\mathrm{C} 646$ and histone $\mathrm{H} 3$ acetylation was then analyzed by immunoblotting. Total H3 was blotted as a loading control. C646 blocks histone H3 acetylation in HepG2, Huh7, HLE and SK-HEP1 cells in a dose-dependent manner.

shown), suggesting C646 mainly reduced the proliferation of HCC cells rather than induced apoptosis.

C646 augments TRAIL-induced apoptotic sensitivity. Since most HCC cells are resistant to TRAIL, we investigated if $\mathrm{CBP} / \mathrm{p} 300$ may be involved in this resistance by analysis of the effects of C646 on TRAIL-induced apoptosis. We incubated HCC cells with different concentrations of TRAIL, with or without C646 for $48 \mathrm{~h}$. Although $20 \mu \mathrm{M}$ C646 did not affect TRAIL-induced apoptotic sensitivity of Huh7 cells (Fig. 4B), C646 augmented TRAIL-induced apoptotic sensitivity in HepG2, HLE and SK-HEP1 cells (Fig. 4A, C and D).
C646 suppresses expression of survivin. In order to elucidate the mechanism of the effect of C646 on TRAIL-induced apoptotic sensitivity, we next used immunoblotting to investigate the effects of C646 on the intracellular expression level of survivin, XIAP and Bcl-xL, as these proteins play an important role in controlling apoptotic pathways. In Huh7 cells, the levels of Bcl-xL, XIAP and survivin did not change following C646 treatment (Fig. 5B). In HepG2, HLE, and SK-HEP1 cells, although the levels of Bcl-xL and XIAP did not change in response to C646 treatment, the level of survivin was reduced in response to $\mathrm{C} 646$ treatment in a dose-dependent manner (Fig. 5A, C and D). The levels of survivin were reduced 

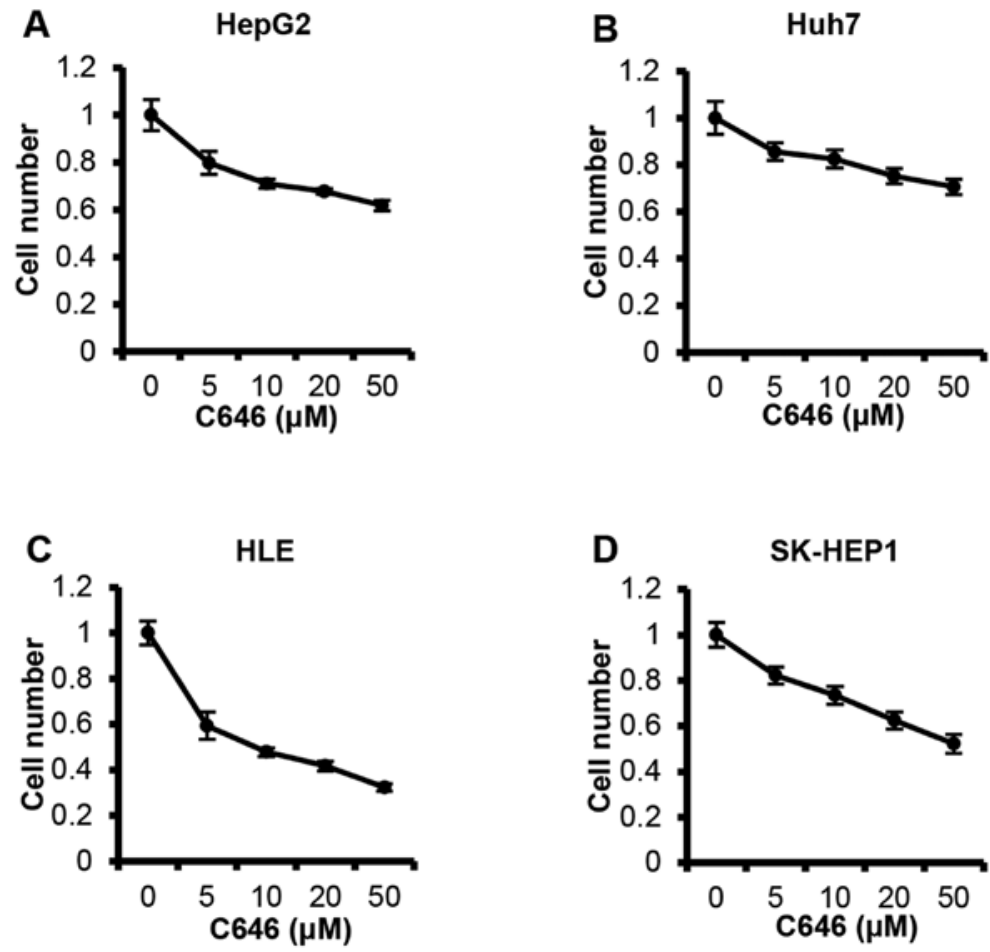

Figure 3. Effects of C646 on HCC cell proliferation. (A) HepG2 cells, (B) Huh7 cells, (C) HLE cells and (D) SK-HEP1 cells were cultured with various concentrations of C646, and cell number was assessed after $24 \mathrm{~h}$ using the MTT assay and expressed relative to the control cells. Data shown are means \pm SD of six independent experiments. C646 decreased cell number of HCC cell lines in a dose-dependent manner.
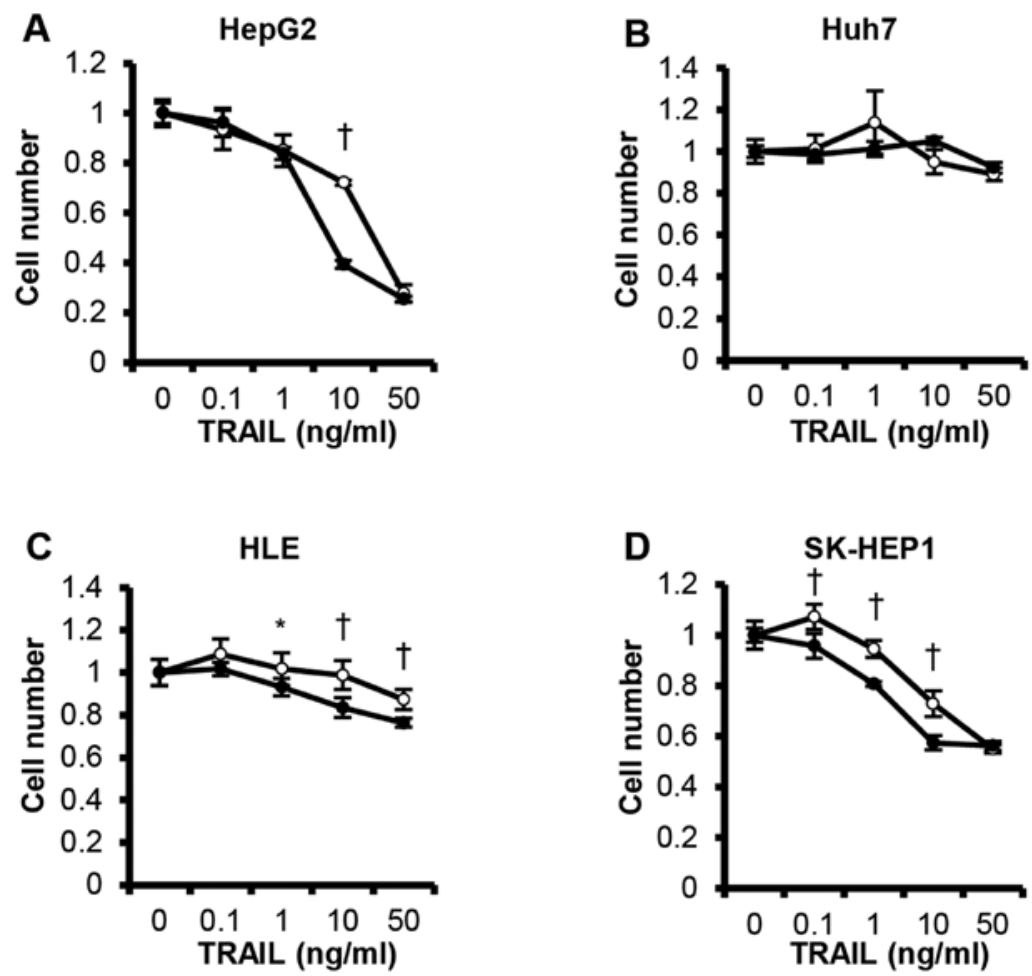

Figure 4. Effects of C646 on TRAIL-induced apoptosis in HCC cells. (A) HepG2 cells, (B) Huh7 cells, (C) HLE cells and (D) SK-HEP1 cells were incubated with $0 \mu \mathrm{M}$ (white circles) or $20 \mu \mathrm{M}$ (black circles) of C646 and with $0-50 \mathrm{ng} / \mathrm{ml}$ TRAIL, and cell number was assessed after $48 \mathrm{~h}$ using the MTT assay and expressed relative to the control cells. Data shown are means $\pm \mathrm{SD}$ of six independent experiments ( $\mathrm{P}<0.05$ and ${ }^{\dagger} \mathrm{P}<0.01 ; 0$ vs. $20 \mu \mathrm{M}$ ).

by C646 treatment in all cell lines except for Huh7, providing a possible explanation for the low sensitivity of Huh7 to C646 augmentation of TRAIL-induced apoptosis.
C646 inhibits the invasion of HCC cells. Finally, we examined the effect of $\mathrm{C} 646$ on $\mathrm{HCC}$ cell invasion using a Matrigel-coated invasion chamber. Interestingly, culture with C646 ( 0,10 or 
A

HepG2

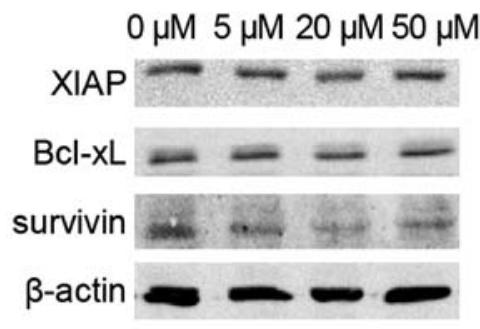

C

HLE

$0 \mu \mathrm{M} 5 \mu \mathrm{M} 20 \mu \mathrm{M} 50 \mu \mathrm{M}$

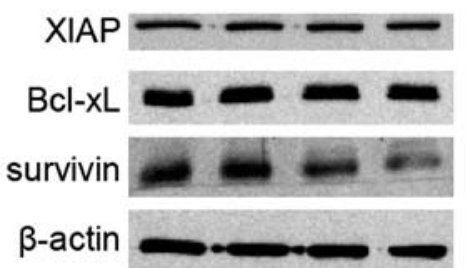

B

Huh7

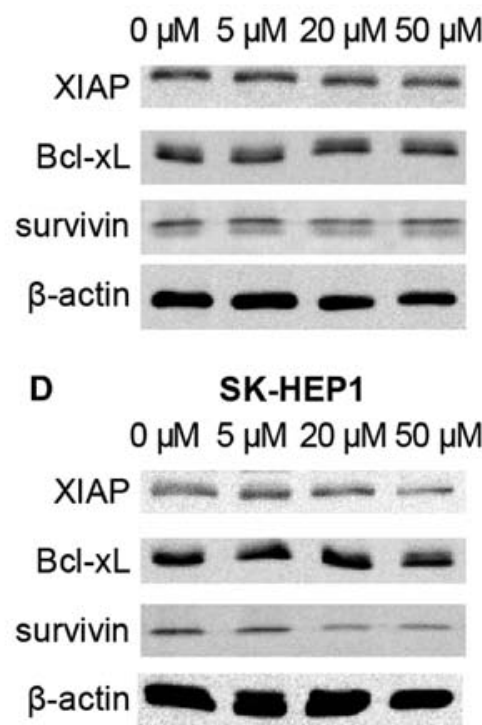

Figure 5. Effects of C646 on expression of apoptosis-related proteins in HCC cells. (A) HepG2 cells, (B) Huh7 cells, (C) HLE cells and (D) SK-HEP1 cells with the indicated concentrations of TRAIL, with or without C646 for $48 \mathrm{~h}$. Cell lysates were then analyzed by immunoblotting for the indicated apoptosis-related proteins. $\beta$-actin was blotted as a loading control.

A HepG2

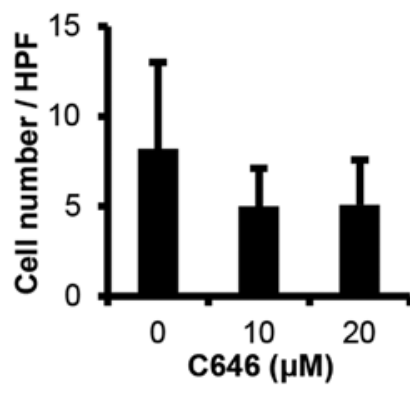

C HLE

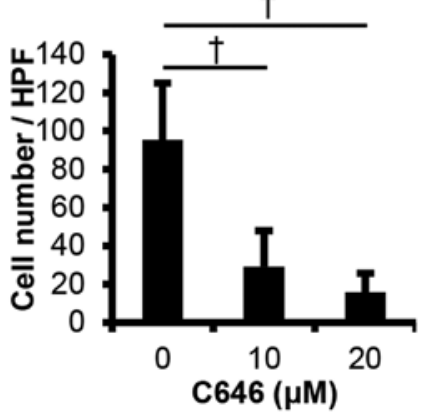

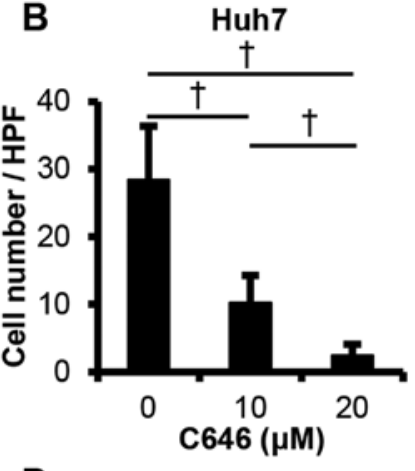

D SK-HEP1

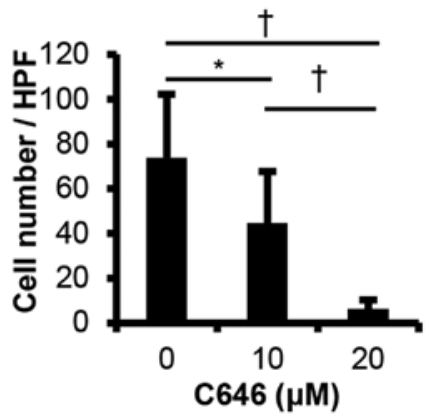

Figure 6. Effect of C646 on HCC cell invasion. (A) HepG2 cells, (B) Huh7 cells, (C) HLE cells and (D) SK-HEP1 cells were incubated with C646 (0, 10 or $20 \mu \mathrm{M})$, and cell invasion was assessed after $22 \mathrm{~h}$ using a BioCoat Matrigel Invasion chamber. Data are expressed as means $\pm \mathrm{SD}\left({ }^{*} \mathrm{P}<0.05\right.$ and $\left.{ }^{\dagger} \mathrm{P}<0.01\right)$.

$20 \mu \mathrm{M})$ significantly inhibited the invasion of Huh7 cells after $22 \mathrm{~h}$ in a dose-dependent manner (Fig. 6B). Similar inhibition of invasion following exposure to C646 was observed for HLE cells (Fig. 6C) and SK-HEP1 cells (Fig. 6D). However, culture with C646 did not significantly inhibit the invasion of HepG2 cells (Fig. 6A).

C646 changes invasion-related mRNA expression in HCC cells. To elucidate the mechanism by which C646 suppresses the invasion of HCC cells, we compared the mRNA expression of Huh7 cells cultured with $20 \mu \mathrm{M}$ C646 with that of control cells using a real-time PCR array. This experiment showed $>1.5$ fold-changes in the mRNA expression levels of MMP15, LAMA3 and SPP1 between the C646-treated and control cells and amplification of these mRNAs was detected at fewer than 30 PCR cycles (data not shown). To confirm these results, we examined C646-induced changes in the level of MMP15, LAMA3 and SPP1 mRNA expression in Huh7 


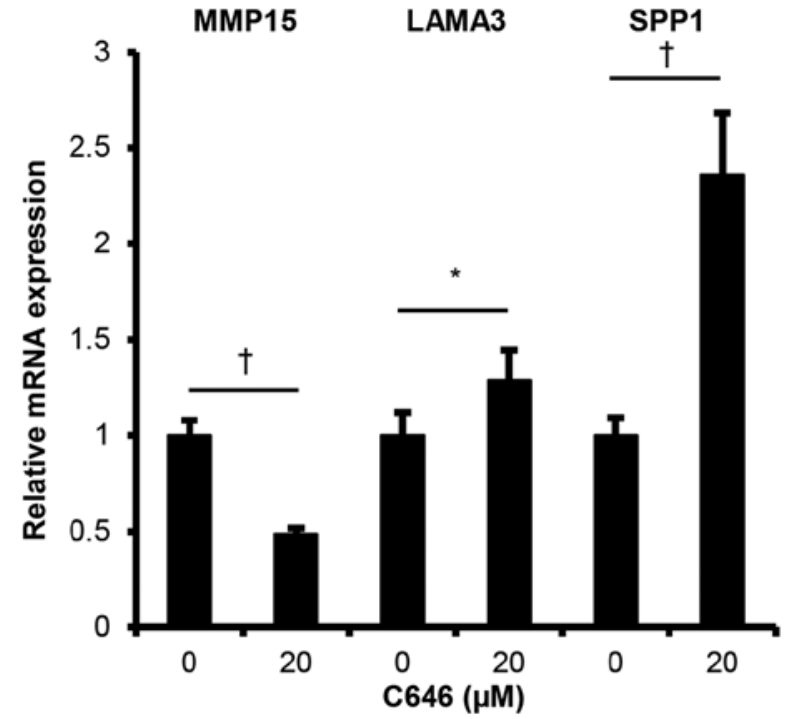

Figure 7. Effect of C646 on the mRNA expression levels of MMP15, LAMA3 and SPP1. The expression levels of target genes in Huh7 cells that were treated with or without the indicated concentrations of $\mathrm{C} 646$ were determined from triplicate qRT-PCR reactions by normalization of expression data to that of GAPDH. Data are expressed as means $\pm \mathrm{SD}\left({ }^{*} \mathrm{P}<0.05\right.$ and $\left.{ }^{\top} \mathrm{P}<0.01\right)$.

cells using qRT-PCR. The level of MMP15 (P<0.01) mRNA expression was significantly reduced, whereas the level of LAMA3 $(\mathrm{P}<0.05)$ and SPP1 $(\mathrm{P}<0.01)$ mRNA expression was significantly increased, in Huh7 cells following exposure to C646 (Fig. 7).

\section{Discussion}

In the current study, we observed that high expression of $\mathrm{CBP} /$ p300 was more frequently observed in HCC tissues than in non-malignant liver tissues and showed the highest frequency in extrahepatic metastatic HCC lesions. Moreover, expression of p300, but not that of CBP was strongly correlated with the degree of cancer cell differentiation in HCC. These results suggested that $\mathrm{CBP} / \mathrm{p} 300$ have a critical role in determination of the biological properties of HCC.

Previous studies indicate that increased expression of CBP/ p300 was observed in a variety of human cancers. In prostate cancer, p300 expression correlates with nuclear alterations of tumor cells, contributes to tumor growth and is a predictor of aggressive features (25). In colon cancer, both CBP and p300 are overexpressed in adenocarcinoma tissues compared with normal mucosae (26). In nasopharyngeal carcinoma (NPC), high expression of p300 is more frequently observed in NPC tissues when compared to the non-neoplastic nasopharyngeal mucosal tissues (27). Similarly, in HCC, high expression of p300 is more frequently observed in HCC tissues when compared to the adjacent liver tissues. Moreover, high expression of p300 is associated with an aggressive feature of HCC and is a strong and independent predictor of cancer-specific survival (28). The above evidence strongly supports the findings we obtained in this study.

We investigated the biological function of $\mathrm{CBP} / \mathrm{p} 300$ in HCC cells using the small molecule competitive CBP/p300 inhibitor C646, which has been shown to selectively inhibit $\mathrm{CBP} / \mathrm{p} 300$ HAT activity (19). We found that proliferation and invasion of HCC cells were significantly inhibited by exposure to C646. Previous studies have shown that C646 induces apoptosis in prostate cancer cells (20) and leukemia cells (23). On the contrary, our results indicated that C646 did not induce apoptosis directly, but augmented TRAIL-induced apoptotic sensitivity. TRAIL, a member of the tumor necrosis factor (TNF) family, selectively induces apoptosis in various transformed cell lines. Furthermore, various types of tumor cells including HCC show resistance to TRAIL-induced signaling. In order to elucidate the molecular basis by which C646 augments TRAIL sensitivity, we examined the expression of the inhibitor of apoptosis (IAPs) proteins that are overexpressed in HCC cells and confer tumor cell survival and proliferation mainly by inhibiting the caspase cascade (29-31). We found that decreased cell proliferation by C646 correlated with decreased levels of survivin. A previous study showed that survivin promotes the proliferation of HCC cells (29). These results indicated that downregulation of survivin protein levels by C646 contribute to its anti-proliferation effects and to its augmentation of TRAIL-induced apoptotic sensitivity.

In addition to antiproliferative and apoptotic effects of C646, we found that C646 substantially inhibited the invasion of HCC cell lines. A previous study showed that inhibition of p300 in prostate cancer cells leads to a decrease in cell migration and invasion (20), which supports our results. To clarify the mechanism by which $\mathrm{C} 646$ inhibited the invasion of HCC cell lines, we examined the effect of C646 on the mRNA expression of various invasion-related genes and found that the mRNA expression of MMP15, LAMA3 and SPP1 mRNA was significantly changed compared to control cells.

MMP15 is classified into the membrane type MMPs that are important for pericellular proteolysis. In the present study, the expression level of MMP15 was significantly decreased by C646 treatment. MMP-15 suppression was previously shown to induce inhibitory effects on the $3 \mathrm{D}$ proliferation and in vivo tumor growth of human fibrosarcoma and gastric cancer cells (32). Furthermore, MMP15 expression is associated with tumor progression and angiogenesis in human lung cancer (33). Our result is consistent with these data. Laminin-5 is a heterotrimer of $\alpha 3, \beta 3$ and $\gamma 2$ subunits, which are encoded by LAMA3, LAMB3 and LAMC2 genes, respectively. Our results showed that decreased invasion of HCC cells correlated with an increased expression level of LAMA3. Laminin $\beta 3$ and $\gamma 2$ chains accumulate intracellularly and play a role in cancer progression, while epigenetic silencing of the laminin $\alpha 3$ chain may lead to an inability to synthesize the basement membrane and may affect cancer cell invasion in gastric cancer (34). Furthermore, the overexpression of p300 in breast epithelial cells leads to decreased levels of expression of LAMA3 and LAMC2, resulting in decreased adhesion (35). SPP1 (also known as osteopontin) is a multifunctional cytokine that impacts cell proliferation, survival, drug resistance, invasion, and stem-like behavior. It is implicated in promoting the invasive and metastatic progression of many cancers (36). Increased expression of SPP1 was inconsistent with inhibitory effects on HCC cell invasion. However, it has been recognized that metastasis regulating genes, such as MMPs, play complex, and often opposing roles in cancer progression.

We acknowledge that our experimental data were obtained from cultured cell lines, and we did not clarify the effect of 
C646 on normal hepatocytes and stromal cells. The relationships between HCC cells and stromal cells remain to be elucidated. Therefore further investigation is required. Also, the precise mechanism through which C646 changes invasionrelated mRNA expression remains to be elucidated.

In conclusion, C646 inhibited cellular proliferation and invasion, and augmented TRAIL-induced apoptotic sensitivity in $\mathrm{HCC}$ cells. Our results suggest that $\mathrm{CBP} / \mathrm{p} 300 \mathrm{HAT}$ activity has an important role in malignant transformation, proliferation, apoptotic sensitivity and invasion in HCC. CBP/p300 could be a promising therapeutic target in HCC.

\section{References}

1. Waldmann T and Schneider R: Targeting histone modifications - epigenetics in cancer. Curr Opin Cell Biol 25: 184-189, 2013.

2. Dawson MA, Kouzarides T and Huntly BJ: Targeting epigenetic readers in cancer. N Engl J Med 367: 647-657, 2012.

3. Dawson MA and Kouzarides T: Cancer epigenetics: From mechanism to therapy. Cell 150: 12-27, 2012.

4. Wang F, Marshall CB and Ikura M: Transcriptional/epigenetic regulator $\mathrm{CBP} / \mathrm{p} 300$ in tumorigenesis: Structural and functional versatility in target recognition. Cell Mol Life Sci 70: 3989-4008, 2013.

5. Bedford DC, Kasper LH, Fukuyama T and Brindle PK: Target gene context influences the transcriptional requirement for the KAT3 family of CBP and p300 histone acetyltransferases. Epigenetics 5: 9-15, 2010.

6. Kalkhoven E: CBP and p300: HATs for different occasions. Biochem Pharmacol 68: 1145-1155, 2004.

7. Borrow J, Stanton VP Jr, Andresen JM, Becher R, Behm FG, Chaganti RS, Civin CI, Disteche C, Dubé I, Frischauf AM, et al: The translocation $\mathrm{t}(8 ; 16)(\mathrm{p} 11 ; \mathrm{p} 13)$ of acute myeloid leukaemia fuses a putative acetyltransferase to the CREB-binding protein Nat Genet 14: 33-41, 1996.

8. Chaffanet M, Gressin L, Preudhomme C, Soenen-Cornu V, Birnbaum D and Pébusque MJ: MOZ is fused to p300 in an acute monocytic leukemia with $\mathrm{t}(8 ; 22)$. Genes Chromosomes Cancer 28: 138-144, 2000.

9. Muraoka M, Konishi M, Kikuchi-Yanoshita R, Tanaka K, Shitara N, Chong JM, Iwama T and Miyaki M: p300 gene alterations in colorectal and gastric carcinomas. Oncogene 12: $1565-1569,1996$.

10. Gayther SA, Batley SJ, Linger L, Bannister A, Thorpe K, Chin SF, Daigo Y, Russell P, Wilson A, Sowter HM, et al: Mutations truncating the EP300 acetylase in human cancers. Nat Genet 24: 300-303, 2000 .

11. Kung AL, Rebel VI, Bronson RT, Ch'ng LE, Sieff CA, Livingston DM and Yao TP: Gene dose-dependent control of hematopoiesis and hematologic tumor suppression by CBP. Genes Dev 14: 272-277, 2000.

12. Rebel VI, Kung AL, Tanner EA, Yang H, Bronson RT and Livingston DM: Distinct roles for CREB-binding protein and p300 in hematopoietic stem cell self-renewal. Proc Natl Acad Sci USA 99: 14789-14794, 2002.

13. Ionov Y, Matsui S and Cowell JK: A role for $\mathrm{p} 300 / \mathrm{CREB}$ binding protein genes in promoting cancer progression in colon cancer cell lines with microsatellite instability. Proc Natl Acad Sci USA 101: 1273-1278, 2004

14. Iyer NG, Chin SF, Ozdag H, Daigo Y, Hu DE, Cariati M, Brindle K, Aparicio S and Caldas C: p300 regulates p53-dependent apoptosis after DNA damage in colorectal cancer cells by modulation of PUMA/p21 levels. Proc Natl Acad Sci USA 101: 7386-7391, 2004.

15. Krubasik D, Iyer NG, English WR, Ahmed AA, Vias M, Roskelley C, Brenton JD, Caldas C and Murphy G: Absence of p300 induces cellular phenotypic changes characteristic of epithelial to mesenchyme transition. Br J Cancer 94: 1326-1332, 2006.

16. Ozen C, Yildiz G, Dagcan AT, Cevik D, Ors A, Keles U, Topel $\mathrm{H}$ and Ozturk M: Genetics and epigenetics of liver cancer. N Biotechnol 30: 381-384, 2013.

17. Pogribny IP and Rusyn I: Role of epigenetic aberrations in the development and progression of human hepatocellular carcinoma. Cancer Lett 342: 223-230, 2014.
18. Ma L, Chua MS, Andrisani O and So S: Epigenetics in hepatocellular carcinoma: An update and future therapy perspectives. World J Gastroenterol 20: 333-345, 2014.

19. Bowers EM, Yan G, Mukherjee C, Orry A, Wang L, Holbert MA, Crump NT, Hazzalin CA, Liszczak G, Yuan H, et al: Virtual ligand screening of the p300/CBP histone acetyltransferase: Identification of a selective small molecule inhibitor. Chem Biol 17: 471-482, 2010.

20. Santer FR, Höschele PP, Oh SJ, Erb HH, Bouchal J, Cavarretta IT, Parson W, Meyers DJ, Cole PA and Culig Z: Inhibition of the acetyltransferases p300 and CBP reveals a targetable function for $\mathrm{p} 300$ in the survival and invasion pathways of prostate cancer cell lines. Mol Cancer Ther 10: 1644-1655, 2011.

21. Yan G, Eller MS, Elm C, Larocca CA, Ryu B, Panova IP, Dancy BM, Bowers EM, Meyers D, Lareau L, et al: Selective inhibition of p300 HAT blocks cell cycle progression, induces cellular senescence, and inhibits the DNA damage response in melanoma cells. J Invest Dermatol 133: 2444-2452, 2013.

22. Oike T, Komachi M, Ogiwara H, Amornwichet N, Saitoh Y, Torikai K, Kubo N, Nakano T and Kohno T: C646, a selective small molecule inhibitor of histone acetyltransferase p300, radiosensitizes lung cancer cells by enhancing mitotic catastrophe. Radiother Oncol 111: 222-227, 2014

23. Gao XN, Lin J, Ning QY, Gao L, Yao YS, Zhou JH, Li YH, Wang LL and Yu L: A histone acetyltransferase p300 inhibitor C646 induces cell cycle arrest and apoptosis selectively in AML1-ETO-positive AML cells. PLoS One 8: e55481, 2013.

24. Fuke H, Shiraki K, Sugimoto K, Tanaka J, Beppu T, Yoneda K, Yamamoto N, Ito K, Masuya M and Takei Y: Jak inhibitor induces $\mathrm{S}$ phase cell-cycle arrest and augments TRAIL-induced apoptosis in human hepatocellular carcinoma cells. Biochem Biophys Res Commun 363: 738-744, 2007.

25. Isharwal S, Miller MC, Marlow C, Makarov DV, Partin AW and Veltri RW: p300 (histone acetyltransferase) biomarker predicts prostate cancer biochemical recurrence and correlates with changes in epithelia nuclear size and shape. Prostate 68: 1097-1104, 2008.

26. Ishihama K, Yamakawa $M$, Semba $S$, Takeda $H$, Kawata $S$, Kimura S and Kimura W: Expression of HDAC1 and CBP/p300 in human colorectal carcinomas. J Clin Pathol 60: 1205-1210, 2007.

27. Liao ZW, Zhou TC, Tan XJ, Song XL, Liu Y, Shi XY, Huang WJ, Du LL, Tu BJ and Lin XD: High expression of p300 is linked to aggressive features and poor prognosis of nasopharyngeal carcinoma. J Transl Med 10: 110, 2012.

28. Li M, Luo RZ, Chen JW, Cao Y, Lu JB, He JH, Wu QL and Cai MY: High expression of transcriptional coactivator p300 correlates with aggressive features and poor prognosis of hepatocellular carcinoma. J Transl Med 9: 5, 2011.

29. Ito T, Shiraki K, Sugimoto K, Yamanaka T, Fujikawa K, Ito M, Takase K, Moriyama M, Kawano H, Hayashida M, et al: Survivin promotes cell proliferation in human hepatocellular carcinoma. Hepatology 31: 1080-1085, 2000.

30. Takehara T, Liu X, Fujimoto J, Friedman SL and Takahashi H: Expression and role of Bcl-xL in human hepatocellular carcinomas. Hepatology 34: 55-61, 2001.

31. Shiraki K, Sugimoto K, Yamanaka Y, Yamaguchi Y, Saitou Y, Ito K, Yamamoto N, Yamanaka T, Fujikawa K, Murata K, et al: Overexpression of X-linked inhibitor of apoptosis in human hepatocellular carcinoma. Int J Mol Med 12: 705-708, 2003.

32. Ito E, Yana I, Fujita C, Irifune A, Takeda M, Madachi A, Mori S, Hamada Y, Kawaguchi N and Matsuura N: The role of MT2-MMP in cancer progression. Biochem Biophys Res Commun 393: 222-227, 2010.

33. Chen L, Zhou Q, Xu B, Liu J, Shi L, Zhu D, Wu C and Jiang J: MT2-MMP expression associates with tumor progression and angiogenesis in human lung cancer. Int J Clin Exp Pathol 7: 3469-3477, 2014.

34. Ii M, Yamamoto $H$, Taniguchi $H$, Adachi Y, Nakazawa M, Ohashi H, Tanuma T, Sukawa Y, Suzuki H, Sasaki S, et al: Co-expression of laminin $\beta 3$ and $\gamma 2$ chains and epigenetic inactivation of laminin $\alpha 3$ chain in gastric cancer. Int J Oncol 39: 593-599, 2011.

35. Miller KA, Chung J, Lo D, Jones JC, Thimmapaya B and Weitzman SA: Inhibition of laminin-5 production in breast epithelial cells by overexpression of p300. J Biol Chem 275: 8176-8182, 2000.

36. Shevde LA and Samant RS: Role of osteopontin in the pathophysiology of cancer. Matrix Biol 37: 131-141, 2014. 